Ana Cecilia Prenz Kopušar

DOI: $10.4312 / v h .24 .1 .231-242$

Universidad de Trieste

(c) (1) ()

\title{
Monseñor Sabetay de Cansinos Asséns: una lectura
}

Palabras clave: sefardíes, reconciliación, temática judía, Cansinos Asséns, Šabetay Djaen.

En el presente trabajo presentamos, a través de la lectura del relato de Rafael Cansinos Asséns, Monseñor Sabetay, publicado en el libro Los judíos en Sefarad. Episodios y Símbolos ${ }^{1}$, el impacto que genera sobre el autor la entrevista con el gran rabino Sr. D. Sabetay Aruk, nombre en clave del dramaturgo sefardí Šabetay Djaen, que tuvo lugar en Madrid durante el periodo de la II República. Planteamos la lectura a partir de dos espacios y experiencias de vida diferentes que, sin embargo, confluyen en muchos puntos. Es decir, por una parte, desde el espacio español a través del proceso de descubrimiento y aceptación del origen judío del escritor Cansinos Asséns y, por otra, desde el espacio bosnio por medio de la labor, también teatral, del dramaturgo de origen búlgaro, Šabetay Djaen, que desarrolló parte de su actividad en Bosnia.

Los judíos en Sefarad. Episodios y Símbolos recoge varios artículos publicados en la revista Judaica de Buenos Aires y en otras revistas. Las narraciones (excepto la primera cuyo tema se desarrolla en 1492) cuentan hechos cotidianos de los personajes que constituyeron la comunidad judía de Madrid de principios del siglo XX. El libro, considerado un antecedente de La novela de un literato - las memorias del autor-, enlaza la historia de los personajes con la del mismo Cansinos, personificado en la figura de Benaser el poeta, descendiente de conversos. Los judios en Sefarad también se presenta como la continuación de Luminarias de Janucá (1924), novela autobiográfica, que revela el proceso interior vivido por el autor frente al descubrimiento y aceptación de su origen judío. La obra representa la búsqueda de una identidad

$1 \quad$ Publicado por primera vez en 1950 en Buenos Aires en la Colección Sefarad de la Editorial Israel con el prólogo de César Tiempo. 
que el personaje, Rafael Benaser, conlleva latente pero olvidada. Como es sabido, Cansinos participó con fervor en la campaña iniciada por el senador Ángel Pulido publicando varios artículos de apoyo a la misma, conoció a las personalidades que participaron en el proceso de acercamiento entre España y las comunidades sefardíes de Oriente y del Norte de África, entre ellos a Abraham Shalom Yahuda, que llega a España en 1913 y es el primer catedrático de Hebreo en la Universidad de Madrid, al crítico y escritor Max Nordau, al senador y académico de la Lengua Española José Farache, todos ellos personalidades que a través de sus reflexiones, pensamientos, emociones, victorias y fracasos son minuciosamente descritos en la obra. Rafael Benaser y el Dr. Salomón (personificación de Abraham Yahuda) son retomados por el autor en el relato que aquí presentamos. El autor desarrolla la novela Luminarias de Janucá sobre dos planos. Por una parte, asistimos al impacto que produce en la sociedad la campaña filo sefardí a través de una crónica que narra la conformación de la comunidad judía, la construcción de la primera sinagoga madrileña en la época moderna, la creación de la Cátedra de Literaturas Rabínicas como resultado de la campaña iniciada por Pulido. Por otra, participamos de los sentimientos más íntimos de los personajes ante la propia causa, de lo cual dan testimonio el paralelismo entre el crecimiento personal del personaje de Benaser y los cambios que se van produciendo en su entorno. Los dos planos, nos permiten proyectar un friso sobre el contexto social y su época al mismo tiempo que, tanto desde la perspectiva de los personajes como a través de las sensaciones, comprender las circunstancias, algunas cruciales, que los judíos vivieron desde su propio interior. «[...] El ojo de Cansinos [...] no actúa como un observador cualquiera, sino amorosamente y con cercanía, como alguien que no puede atravesar el umbral que le separa de los observados pero que siente que todos esos personajes son sus hermanos» (Israel Garzón, 2006: 29).

El judaísmo de Cansinos fue tratado por los críticos desde distintas perspectivas. A menudo, las lecturas fueron discordantes; sin embrago, como indica Garzón, el autor «se sintió judío no sólo en un sentido laico sino también religioso durante muchas etapas de su vida» (Israel Garzón, 2006: 15). Educado en la fe católica, ya desde temprano investigó el origen de su apellido y de su familia de descendencia conversa. Se movió, pues, entre las dos culturas religiosas que se integraban en su interior. Decía de sí «que esa libertad le servía para dar su amén a todos los responsos. Para pronunciar el réquiem y el shalom» (Israel Garzón, 2006: 15). 
Šabetay Yosef Djaen² es el personaje al que Cansinos Asséns dedica las páginas de su relato. Se trata de un intelectual sefardí, reconocido por su labor en defensa de la cultura y la lengua judeoespañolas, que luchó por el reconocimiento de los derechos de los sefardíes en España y que fue rabino de Buenos Aires y de Bucarest y gran rabino de las comunidades sefardíes de Argentina. Djaen, que como Cansinos se involucró activamente en la causa sefardí, produce parte de su obra dramática durante su estadía en Bosnia en las primeras dos décadas del s. XX. Allí vive primero en la ciudad de Travnik y más tarde en Sarajevo. Desarrolla la función de gabay en el templo, es maestro de hebreo e inspector en las escuelas judías hasta la caída del Imperio austrohúngaro. Conocido y representado en Bosnia, Serbia, Bulgaria, Grecia, Turquía, Rumania, Egipto y América se destaca por su escritura directa y sentida. Intelectuales y críticos como Moric Levi, Kalmi Baruh y Benjamin Pinto primero, y Avram Pinto, Muhamed Nezirović, Krinka Vidaković, Elena Romero, Amor Ayala y otros escribieron sobre este escritor, sobre sus obras dramáticas y la repercusión que tuvieron en la época. Sabemos que las mismas fueron representadas, sea en Sarajevo, sea en las ciudades del interior de Bosnia (Nezirović, 1992: 538)3. Él mismo Djaen escribe en el prólogo a la obra Yiftab que «en los últimos años vide jugar mi drama Yiftah, no de parte de amatores, sino de artistas en teatros del Estado de Yugoslavia» (Romero, 1992: 280). También afirma que sus obras «Yiftah, Débora, Del mundo de ariba y del mundo de abajo ya fueron traducidas en lingua serba y jugadas en Belogrado, en Sarayevo y en otros lugares» (Romero, 1992: 280). Elena Romero constata que «ésta es la única noticia expresa que nos ha llegado acerca de un teatro sefardí traducido a otras lenguas» (1992: 280). Este dato denota el interés, propio de la época y en Bosnia, por la cultura, la lengua y la literatura sefardíes, sea las que se generan en el propio territorio, sea las que llegan de otros países cercanos. Avram Pinto (1987: 119) nota con respecto a las obras dramáticas de Djaen que «svoje drame pisao je latinicom na ladino jeziku, pisaćom mašinom $»^{4}$. «Nije imao sredstava da ih štampa, a niti su štampari imali razumevanja za štampanje drama, koje su se vrlo slabo kupovale»5. Tres obras de Djaen fueron impresas en aquellos años en Viena (1921-1922) por la editorial

2 Pleven 1883 - Tucumán 1947.

3 La pieza teatral Bar Kojbá fue representada en la ciudad de Zenica en el año 1904 en ocasión de la consagración de la sinagoga de la ciudad. Esta obra fue asimismo traducida al serbocroata. Déborah 1917, Lijepa pjesma 1919.

$4 \ll[\ldots]$ escribía en alfabeto latino, en ladino y a máquina».

Las traducciones son de la autora del artículo.

5 «No tenía recursos para imprimirlas, tampoco los impresores tenían comprensión por la edición de dramas, que se compraban poco». 
Unión: Yiftah, Débora y La bija del sol. Las primeras dos de tema bíblico, la tercera, según Romero, «una fantasía alegórica (brujas, diablos...) en verso y de intención moralizante» (1992: 281). Nezirović en el libro Jevrejsko Španjolska Književnost (1992) presenta algunos de los textos de Djaen que con certeza fueron escritos durante la permanencia en Bosnia en judeoespañol y que según el estudioso representan el ápice de su teatro. Estamos hablando de El bello poema (Lijepa pjesma), pieza en dos actos lo mismo que La bija del sol, en verso, Débora y Yiftab. Probablemente Djaen haya escrito en Bosnia también Déguel Šion y Los progromes de Kichinov. El hispanista sarajevita Kalmi Baruh (1972: 325) en 1925 alaba el temperamento poético de Djaen: «Treba ga jednom slušati sa propovedaonice ili ma sa kakve tribine i namah ćete se uveriti da on ima i fantazije i osećanja i dikcije u meri koja znatno prevazilazi prosećnost. On ima jevrejskog obrazovanja, koje je poslužio kao vrelo motiva za njegove radove», más adelante agrega que en sus dramas hay «vrlo lepih poetskih elemenata», ${ }^{6}$ sin embargo advierte la falta de conocimiento de las reglas de la escritura dramática por parte del autor. Ve en sus obras cierta pretensión, patetismo y declamación y la incapacidad de haber sabido aprovechar su talento poético.

Da je on, recimo, ona mnoga mesta u svojim dramama - koja tamo figuriraju kao neumesne tirade - obradio u formi kraćih epskih spevova, ovi spevovi ako ni po čemu drugom, a ono po sadržini svojoj, postali nekom vrstom narodne poezije, i kao takvi imali bi i nacionalnu i odgojnu vrednost ${ }^{7}$.

Unos años más tarde, Benjamin Pinto (cit. en Nezirović, 1992: 546) también destaca el talento poético de Djaen. Escribe: «rečenica im je divna! Jezik im je bogat, živopisan i suvereno žongliraju njime. I na ova razmišljanja potakao me je njihov jezik, koji nije naš, koji se razlikuje od našeg i zbog toga se razlikuje od našeg» ${ }^{8}$. Propiamente es el aspecto lingüístico el que lleva a los críticos

6 «Hay que escucharlo alguna vez desde el púlpito o desde cualquier tribuna y se convencerán que él tiene fantasía y sentimiento y dicción en la medida que supera significativamente el promedio. Tiene una educación y cultura judía que le sirvieron como fuente de motivos para sus trabajos», más adelante agrega que en sus dramas hay «elementos poéticos muy bonitos».

7 «Por ejemplo, si él hubiera elaborado unos cuantos fragmentos de sus dramas - que figuran como discursos fuera de lugar- en forma de poemas épicos breves, estos poemas, por lo menos por su contenido, se hubieran convertido en una especie de poesía popular, y como tales tendrían su valor nacional y educativo».

8 «sus frases son hermosas [también refiriéndose a las de Cappon]! La lengua es rica, colorida y con maestría hacen malabares con ella. Estas reflexiones me las ha generado su lengua, que no es la nuestra, que se diferencia de la nuestra y por ello mismo se diferencia de la nuestra». 
mencionados a la comparación con la lengua y escritura de Laura Papo Bohoreta, dramaturga sefardí de Sarajevo, considerada la autora que había logrado transmitir el habla, las costumbres y el sentir propio de su ciudad.

Cansinos, en el relato Monseñor Sabetay, expresa total admiración hacia Šabetay Djaen que, como Abraham Aaron Cappon - reconocido por su obra y labor cultural en Bosnia a través de la revista La Alborada-, provenía de Bulgaria.

Moreno, de un tono oliváceo que se descomponía en pura palidez cuando se lo miraba atentamente, llegando a ser casi blancura. Los ojos pequeños y oblicuos, tenían la mirada del Asia; la mirada enigmática y poderosa de las figuras sacerdotales en los bajorrelieves antiguos (2006: 120).

El relato sitúa a los personajes en dos sitios distintos: en un primer momento, en la casa de Benaser, durante una visita breve y formal que Sabetay le hace al poeta -que incisivamente destaca la visita de muchas personas ilustres a su casa convertida, como escribe, en «una puerta de Israel» (2006: 119); más tarde, en una terraza de la calle de Alcalá, en el centro de Madrid, durante una charla informal entre ambos.

En su proceder los dos personajes expresan expectativas diferentes. La entrevista, escribe Cansinos «fue ceremoniosa en medio de la cordialidad» (Ibíd.). El rabino cuya actitud discreta se centra en su rol y funciones, visita a Benaser para pedirle ayuda «para la causa sefardí» (Ibíd.). También expresa estima y admiración hacia el anfitrión: «[...] no habría venido de tan lejos por ver a un potentado; pero habría andado más aún por ver el rostro del cantor de Las luminarias de Janucá» (Ibíd.).

Benaser, en cambio, vive la presencia del rabino desde una perspectiva personal. Expresa intensa veneración y se siente emocionado. Se abstrae en sus pensamientos, en esa reconstrucción de su identidad judía, y proyecta sobre Sabetay la figura de un sumo sacerdote hebreo decorándolo con el efod, es decir el pectoral que llevan los sumos sacerdotes. Absorto en sus pensamientos, dice que nunca había visto a un gran rabino, tanto que «contemplaba con emoción a aquel caballero venerable de cabello casi blanco y ojos refulgentes y jóvenes que llegaba a su casa en compañía de dos adolescentes como un rabí talmúdico» (2006: 119). La emoción que experimenta ante la presencia de su huésped, descripta con vivos matices, se enlaza con el linaje personal y la tradición institucional del mismo: «iEs un gran rabí, un cohen el que tengo en mi casa; el hombre que puede dar la berajá» (2006: 120). 
En la segunda parte del relato, más distendida, confidencial, cotidiana, «sentados ante dos casos de refrescos con soda» (2006: 121) el rabino manifiesta sus impresiones entusiastas después de la visita a Toledo y reflexiona sobre la etimología del nombre de la ciudad: para él Tultul, el tránsito, referido a la ciudad del tránsito de raza, alusión a las tribus que venían de Judea y no Toledot, las generaciones, como insinúa el poeta Benaser.

La topografía de Toledo es la misma que la de Jerusalén. En un alto rodeada de pueblecitos que no pueden ser más judaicos. ¡Maqueda, Askalen! ... No me cabe duda que los emigrantes judíos quisieron reproducir, con un sentido místico, el mapa de Jerusalén (2006: 121).

El poeta ve en esta interpretación etimológica extrema belleza y por ello decide no hacer objeciones. Tal es el encanto vivido por el gran rabino ante la visión de la ciudad que Benaser prefiere destacar su vena poética. Djaen exclama: «!Sí yo soy un poeta! ¡Quizás sea solo eso! ¡He escrito dramas, dramas históricos de mi raza y versos, muchos versos» (Ibíd.) y a Benaser, mientras Djaen recita versos en «castellano arcaico» (Ibíd.) le parece estar escuchando al Rabí Sem Tob.

Ya desde las primeras páginas del relato Monseñor Sabetay también emerge uno de los temas que más caracteriza la novela Luminarias de Janucá, es decir, el cristianismo presente y determinante en la vida de los personajes de Rafael Benaser y su hermana. Cansinos coloca al personaje de Benaser en el cruce de dos culturas. El mismo nace y crece en la tradición cristiana pero en el transcurso de la novela vemos como va adquiriendo la tradición de sus antepasados judíos. Incorpora la cultura y religión judía como propia pero no logra prescindir de la percepción de la misma como de un destino fatal. En este texto nos encontramos ante una especie de simbiosis que el autor vive entre su pertenencia a la cultura/religión católica y a la de sus antepasados, la judía. No se trata de una mera contigüidad entre dos culturas y dos religiones, sino de un momento que el personaje siente como una verdadera integración en un unicum indisoluble. En el acto de acompañar a la hermana en el descubrimiento de sus orígenes, hermana que vive de manera angustiosa y conflictiva este proceso, el mismo Rafael Benaser expresa el deseo profundo de coexistencia entre las dos tradiciones. Lo expresa a través de una comparación entre Cristo y un hombre (no importa cuál hombre) «entre las llamas de una hoguera».

La sospecha sola de que por nuestras venas puede correr una gota siquiera de esa sangre que una vez fue vertida en un 
cadalso, como la de Cristo, para apaciguar el rencor de una plebe fanática, solamente esa sospecha, que hace que nuestro vello se erice de un espanto piadoso, y un frío más solemne que el de un desmayo pueril recorra nuestro cuerpo, y nuestra alma, compadecida e indignada, se subleve como por una afrenta ahora mismo sufrida, bastaría para que nosotros aceptásemos toda la grandeza y el horror de ser su prole y afirmáramos nuestra posible consanguinidad con ese muerto santo; para que vertiésemos lágrimas sobre su memoria y llorásemos con grandes gritos sobre su sepulcro vacío; para que su fe nos fuera cara, y para que delante de todos lo confesáramos, como al Cristo mismo, aunque de nuevo, al hacerlo así, arrostrásemos unas hogueras, quién sabe si no para siempre extinguidas. Porque al hacerlo así, hermana mía, al confesar nuestro ese cadáver calcinado, nos confesamos también de la estirpe de Cristo. (Cansinos, 2011: 45-46)

Se desprende de este fragmento el profundo deseo del autor de poner fin a las divisiones, de articular a través de un reconocimiento de los unos en los otros, la conjugación de las dos tradiciones.

En el relato Cansinos introduce este tema de manera delicada. Alude al mismo y apenas en las páginas siguientes lo desarrolla. Destaca la dualidad cultural y religiosa que le es propia a través de la presencia de un cuadro de la Virgen.

El Sr. Sabetay sentó su judaísmo en el viejo hogar en que días antes reposara su catolicismo un sacerdote de la Iglesia, y pareció un patriarca de la antigua ley entre las imágenes de las Madonas que decoraban los muros y que fingió no ver. (Culto sencillamente a la mujer, a la Madre que Benaser se complacía en contemplar divinizada por el recuerdo de la suya).

En el relato asistimos de manera reiteradaa esta conexión entre los dos modos de ser, como un leitmotiv, donde nada impide que un sacerdote de la Iglesia católica y un gran rabino (en su casa considerada por el autor una puerta de Israel) compartan y totalicen un mismo espacio.

Benasser en el proceso de aceptación de su identidad también judía, desarrolla una intensa y fervorosa búsqueda de figuras que activamente participaban en la campaña filo sefardí y que podían ampliar su horizonte de conocimientos sobre los sefardíes. Sin ir más lejos, visita al doctor Miguel Florido (nombre 
del personaje que encarna al senador A. Pulido) y encuentra al Dr. Salomon (Yahuda), personaje fundamental que también retoma en el relato.

En la conversación que llevan a cabo los personajes, Djaen recuerda haber oído hablar de la admirable labor de Benaser (Cansinos Asséns) por el Dr. Salomón, en la realidad, como hemos mencionado, el profesor, escritor y lingüista Abraham Shalom Yahuda, considerado por los personajes un verdadero jajám, sabio. A partir de aquí el autor realiza una serie de reflexiones que se reiteran en sus obras y que remiten a la idea de la raza judía como «desventurada y triste» (2006: 123). En una página emotiva y a raíz del comentario que le hace Djaen a Benaser sobre lo que solía decirle el Dr. Salomón, «iMira, yo soy más viejo que tú, así que ven aquí y escúchame!» (2006: 122), el autor, que había conocido en su juventud a Abraham Yahuda, reflexiona sobre el vocablo 'viejo' y sobre la vertiginosidad del tiempo: «Todos sus recuerdos se ponían a correr hacia atrás con una velocidad mareante. Las horas le golpeaban la cara como una lluvia» (Ibíd.). Esta vertiginosidad hace que se abstraiga de la realidad y, visualmente, reflexione sobre el hecho de que, antes o después, todo judío se encuentra ante el muro de los lamentos. Remitiéndose a los hechos históricos, imagina a Jerusalén como un «patio de asilo» (Ibíd.) donde los hebreos son harapientos y viejecitos y que «Inglaterra acogía [...] por piedad» (Ibíd.). «Jerusalén era como un hoyo que los atraía desde dondequiera que estuviesen, llamándolos con su boca silbante. Y todos - doctores, banqueros- iban allí alguna vez en su vida para convertirse en seguida en unos miserables, más sin patria allí que en parte alguna» (Ibíd.). Esta imagen le hace sentir piedad hacia estos seres ilustres y sin embargo tan poco considerados; las «grandezas de los judíos», escribe, son «reconocidas sólo por ellos mismos» (2006: 123).

Lo reconforta la aparición durante el encuentro de otro personaje, el Sr. Klein, de personalidad humilde y respetuosa que se lamenta por la actitud irrespetuosa de ciertos marroquíes en el templo: «al verlos allí sentados, mientras Su Eminencia estaba de pie» (2006: 123). A lo que el autor agrega que «los judíos son todos unos pobrecitos que ni entre ellos se respetan» (2006: 123). «Sin embargo, allí estaba aquel Sr. Klein, tan comedido. Sintió por él una gran simpatía. Y por todo Israel. Desde aquel momento empezó a llamar Monseñor a Sabetay» (2006: 123).

Impresionado por el gesto de Klein, Benaser le atribuye a Šabetay la dignidad (como Klein) pero lo hace apelando a una dignidad católica y lo llama Monseñor. 
El relato concluye con la constatación de profunda tristeza que atrapa al autor, él mismo descendiente de judíos que algún día también visitaría aquel patio de asilo y encontraría al Dr. Salomón, ya viejo y que le diría las mismas palabras que le dijo a Djaen y «le contaría muchas penas, todas las penas de Israel [...] Y él lo escucharía sollozando, muchas noches [...] muchas noches, hasta que al fin los bañare en su luz la nueva aurora de Sión [...] Las noches bajo aquel cielo son breves» (2006: 124). Cansinos deja un final abierto que parece recordar los versículos del Libro de Isaías, capítulo 21:11 (Oráculo sobre Dumá): «Alguien me grita desde Seír: / «Centinela, ¿cuánto queda de la noche? / Centinela, ¿cuánto queda de la noche?» / 21:12 El centinela responde: / «Llega la mañana y de nuevo la noche [...] /». En las noches «breves» de Cansinos queremos leer una luz de esperanza por parte del autor no obstante su marcar cíclico del tiempo y de los eventos en el relato.

Jorge Luis Borges escribió de Cansinos que era un «maestro de una prosa feliz que siempre logra[ba] la belleza y nunca parec[ía] buscarla» (Borges: 1969). También en su colección de poemas El otro, el mismo le dedicó algunos versos. «La imagen de aquel pueblo lapidado / y execrado, inmortal en su agonía / en las negras vigilias lo atraía / con una suerte de terror sagrado. / Bebió como quien bebe un hondo vino / los Psalmos y el Cantar de la Escritura / y sintió que era suya es dulzura / Y sintió que era suyo aquel destino. / Lo llamaba Israel $[. .] /$.$» . Cansinos se consideró un nexo, un vínculo, un puente entre dos$ culturas y religiones. Esto lo plasmó en sus obras. No es casual, pues, que los versos de Borges se encuentren en este libro. La labor artística e intelectual del escritor y «poeta judeo-andaluz», como lo definió el escritor argentino, fue articular los dos mundos culturales a los que pertenecía.

\section{Bibliografía}

Ayala, A. (2005): «'Me vo dedikar enteramente al teatro djudio...' Teatro sefardí de temática nacionalista judía: Iftakh de Sh. Y. Djaen (Viena, 1921)». En: Theatralia 7, 161-174.

Cansinos Asséns, R. (2006) [1950]: Los judios en Sefarad. Episodios y Símbolos. Madrid: Arca Ediciones. Introducción de Jacobo Israel Garzón.

Cansinos Asséns, R. (2006): «Monseñor Sabetay». En: Los judíos en Sefarad. Episodios y Símbolos. Madrid: Arca Ediciones, 119-124.

Cansinos Asséns, R. (2011): Las luminarias de Janucá. Madrid: Arca Ediciones. 
Baruh, K. (1972): «Nekoliko pojava lepe književnosti kod bosanskih Sefarada». En: Izabrana djela. Sarajevo: Svjetlost, 323-328.

Borges, J. L. (1969): «Cansinos y Las mil y una noches». En: La Nación, Buenos Aires 10 de julio.

Garzón, J. I. (2006): Introducción. En: Los judios en Sefarad. Episodios y Símbolos. Madrid: Arca Ediciones, 9-30.

Levi, M. (1922): «Tri drame Sabataja Đaena». En: Židovska svijest, 162, 3.

Nezirović, M. (1992): Jevrejsko-španjolska književnost. Sarajevo: Svjetlost.

Pinto, A. (1987): Jevreji Sarajeva i Bosne i Hercegovine. Sarajevo: Veselin Masleša.

Pinto, B. (1935): «Nešto malo o literarnom stvaranju na jevrejsko-španskom kod nas». En: Jevrejski glas, 41, 2.

Romero, E. (1992): La creación literaria en lengua sefardí. Madrid: Mapfre.

Romero, E. (1979): El teatro de los sefardies orientales. Madrid: CSIC, T. I, 639.

Romero, E. (1983): Repertorio de noticias sobre el mundo teatral de los sefardíes orientales. Madrid: CSIC.

Vidaković, K. (1990): Kultura španskib jevreja na jugoslovenskom tlu. Sarajevo: Svjetlost.

Ventura de Bialek, R. (2010): «Aportes para una biografía del Gran Rabino Sabetay J. D’Jaén». En: Sefárdica 19, 77-92. 


\section{Ana Cecilia Prenz Kopušar}

University of Trieste

\section{Cansinos Asséns's Monseñor Sabetay: a Reading}

Keywords: Sephardim, reconciliation, Jewish themes, Cansinos Asséns, Šabetay Djaen

This paper aims to present the short story Monseñor Sabetay by the Spanish writer Rafael Cansinos Asséns published in the book The Jews in Sefarad. Episodes and Symbols. This text, intense and poetic, tells the story of the meeting between the author and the great Rabbi and Sephardic playwright of Bulgarian origin Šabetay Djaen which took place in Madrid during the period of the Second Republic. The work discusses not only the meeting between the two writers but also the process of reconciliation between the Spanish and the descendants of the Spanish Jews, expelled in 1492, from different, though partially convergent, cultural spaces and experiences. Here the Castillian Spanish space, represented by the writer Cansinos Asséns, whose Jewish origin is acknowledged, and the Bosnian space, represented by the work of the playwright Šabetay Djaen, whose literary development tool place partly in Bosnia, come together. Some characteristics of Cansino's Jewish works are highlighted in the story and the dramatic work of Šabetay Djaen is also presented through the critical readings of his work by some contemporary intellectuals and scholars in Bosnia. 


\section{Ana Cecilia Prenz Kopušar}

Univerza $v$ Trstu

\section{Monseñor Sabetay Cansinosa Assénsa}

Ključne besede: sefardi, sprava, judovska tematika, Cansinos Asséns, Šabetay Djaen

Prispevek predstavlja kratko zgodbo Monseñor Sabetay španskega pisatelja Rafaela Cansinosa Assénsa, ki je bila objavljena v knjigi Los judios en Sefarad. Episodios y Símbolos. Gre za kratko, a zgoščeno in poetično pripoved o avtorjevem srečanju $z$ velikim sefardskim rabinom in dramatikom bolgarskega rodu Šabetayem Djaenom v Madridu v času druge republike. Prispevek pa se ne posveča le srečanju dveh piscev, temveč ponuja razmislek o procesu sprave med Španci in potomci španskih Judov, izgnanimi leta 1492, in sicer iz dveh prostorskih perspektiv in skozi dvoje izkušenj (ki pa v številnih pogledih sovpadata) - po eni strani torej z vidika Španije skozi odkrivanje in sprejemanje judovskega izvora pri pisatelju Cansinosu Assénsu, po drugi strani pa z vidika Bosne, preko (tudi gledališkega) opusa dramatika Šabetaya Djaena, ki je deloma deloval v Bosni. Prispevek predstavlja nekatere značilnosti Cansinosovih del z judovsko tematiko, pa tudi dramatiko Šabetaya Djaena, in sicer na podlagi študij o njegovem delu, ki so jih v njegovem času napisali bosanski misleci in znanstveniki. 